\title{
Long-Term Characteristics of Hazelnut Allergy in an Adjuvant-Free Mouse Model
}

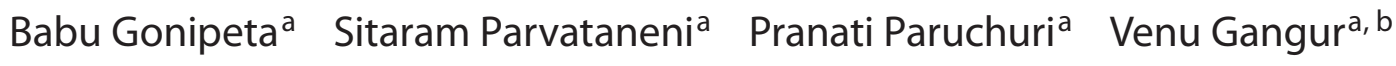 \\ a Food Allergy and Immunology Laboratory, Department of Food Science and Human Nutrition, and \\ ${ }^{b}$ National Food Safety and Toxicology Center, Michigan State University, East Lansing, Mich., USA
}

\section{Key Words}

Hazelnut allergy, natural history · Systemic anaphylaxis •

Immunoglobulin E $\cdot$ T helper 2 lymphocyte profile $\cdot$

Mouse model, adjuvant-free $\cdot$ Food allergy

\begin{abstract}
Background: Clinically it is recognized that tree nut allergies such as hazelnut allergy are not usually outgrown. Specific mechanisms underlying the persistence of such food allergies are incompletely understood. Here we studied the natural history and the long-term immune and clinical characteristics of hazelnut allergy in an adjuvant-free mouse model. Methods: BALB/c mice were sensitized to hazelnut protein using a transdermal sensitization protocol that does not use adjuvant. After establishing sensitization, exposure to hazelnut was withdrawn for 3, 5 or 8 months. The fate of circulating IgE antibodies was monitored. Subsequently, mice were given booster exposures and examined for memory IgE antibody and spleen cell IL-4 responses. Clinical characteristics and hypothermia responses upon oral allergen challenge were studied. Results: Upon allergen withdrawal, circulating hazelnut-specific lgE antibody levels began to drop. Nevertheless, IgE responses once established remained at significantly high levels for up to 8 months (the last time point studied) despite withdrawal of allergen exposure. Memory lgE responses to booster exposures were ro-
\end{abstract}

bust after 3, 5 or 8 months of allergen withdrawal. Furthermore, significant clinical reactivity to oral hazelnut challenge, and hypothermia responses were demonstrable at each of these time points. Long-lasting spleen cell memory IL-4 responses to hazelnut were detectable in these mice explaining the mechanism of sustenance of IgE responses and clinical sensitization. Conclusions: Hazelnut allergy once established persists for long periods, despite withdrawal of allergen exposure, due to long-lasting, memory IgE and IL-4 responses.

Copyright $\odot 2010$ S. Karger AG, Basel

\section{Introduction}

Food allergies that are mediated by IgE antibodies afflict $6-8 \%$ of children and approximately $2-4 \%$ of adults in westernized countries including Europe and the USA $[1,2]$. Any IgE-mediated food allergy has the potential to trigger life-threatening systemic anaphylaxis in humans [2]. However, peanut and tree nut allergies are disproportionately linked to severe, potentially fatal anaphylactic reactions $[3,4]$. Furthermore, whereas milk and egg allergies are generally outgrown in most cases, peanut allergy has been reported to be rarely outgrown (approx. 20\% cases) [5-8]. It is also reported that approximately $9 \%$ of children with tree nut allergies such as cashew nut, wal-

\section{KARGER}

(C) 2010 S. Karger AG, Basel

Fax +41613061234 E-Mail karger@karger.ch www.karger.com www.karger.com/iaa
Correspondence to: Dr. Venu Gangur

Food Allergy and Immunology Laboratory

Department of Food Science and Human Nutrition, Michigan State University 302-B GM Trout Building, East Lansing, MI 48823 (USA)

Tel. +1 517355 8474, ext. 134, Fax +1 517353 8963, E-Mail gangur@anr.msu.edu 
nut and pecan will outgrow their allergy [9]. In contrast, hazelnut allergy, once initiated, is thought to persist for life in humans for reasons that are not completely understood $[10,11]$.

The mechanisms underlying the reason why some IgE-mediated food allergies are outgrown while others remain persistent are incompletely understood at present [12-14]. Thus, Turcanu et al. [15] reported that children who outgrew peanut allergy exhibited a shift in their peripheral blood lymphocyte profile from Th2 to a Th1 phenotype. In contrast, those who remained allergic maintained a Th2-dominated profile [15]. In milk and egg allergy, there are similar reports implicating either Th1/Th2 imbalance or involvement of CD4+ CD25+ T regulatory cells in outgrowing clinical sensitivity [16-18]. In contrast to these food allergies, the mechanism underlying the persistence of tree nut allergies in general and hazelnut allergy in particular is largely unknown.

We have previously reported an adjuvant-free mouse model of hazelnut allergy [19]. The major features of this model include: (i) induction of dose-dependent IgE antibody response to transdermal hazelnut protein exposure; (ii) clinical signs of systemic anaphylaxis and hypothermia response upon oral challenge with hazelnut, and (iii) significant type 2 cytokine responses to hazelnut. Although this model resembles many features of human disease, it is not known whether hazelnut allergy once established would persist in this model as it does in humans.

To address this question, we studied the long-term characteristics of hazelnut allergy in this mouse model. We found that the memory IgE response to hazelnut persists up to 8 months even after allergen withdrawal. A long-lasting memory IgE response is associated with the memory IL-4 response and clinical reactivity to oral hazelnut exposure.

\section{Material and Methods}

The following materials were purchased from sources as indicated in the parentheses: hazelnut protein extract (Greer Laboratories, Lenoir, N.C., USA); protein content was measured by the Lowry-Folin assay; the lipopolysaccharide content of this material was tested and found to be $<0.5 \mathrm{pg} / \mathrm{mg}$ of protein as measured by the Limulus amebocyte lysate assay (Cambrex Bio Science Walkersville Inc., Walkersville, Md., USA); biotin-conjugated rat antimouse IgG1 and IgE antibodies; paired antibodies and recombinant standards for mouse IL-4 (BD Pharmingen, San Diego, Calif., USA); $p$-nitrophenyl phosphate (Sigma, St. Louis, Mo., USA); streptavidin alkaline phosphatase (Jackson Immunoresearch, West Grove, Pa., USA); protein G (GE Health Care, N.J., USA).

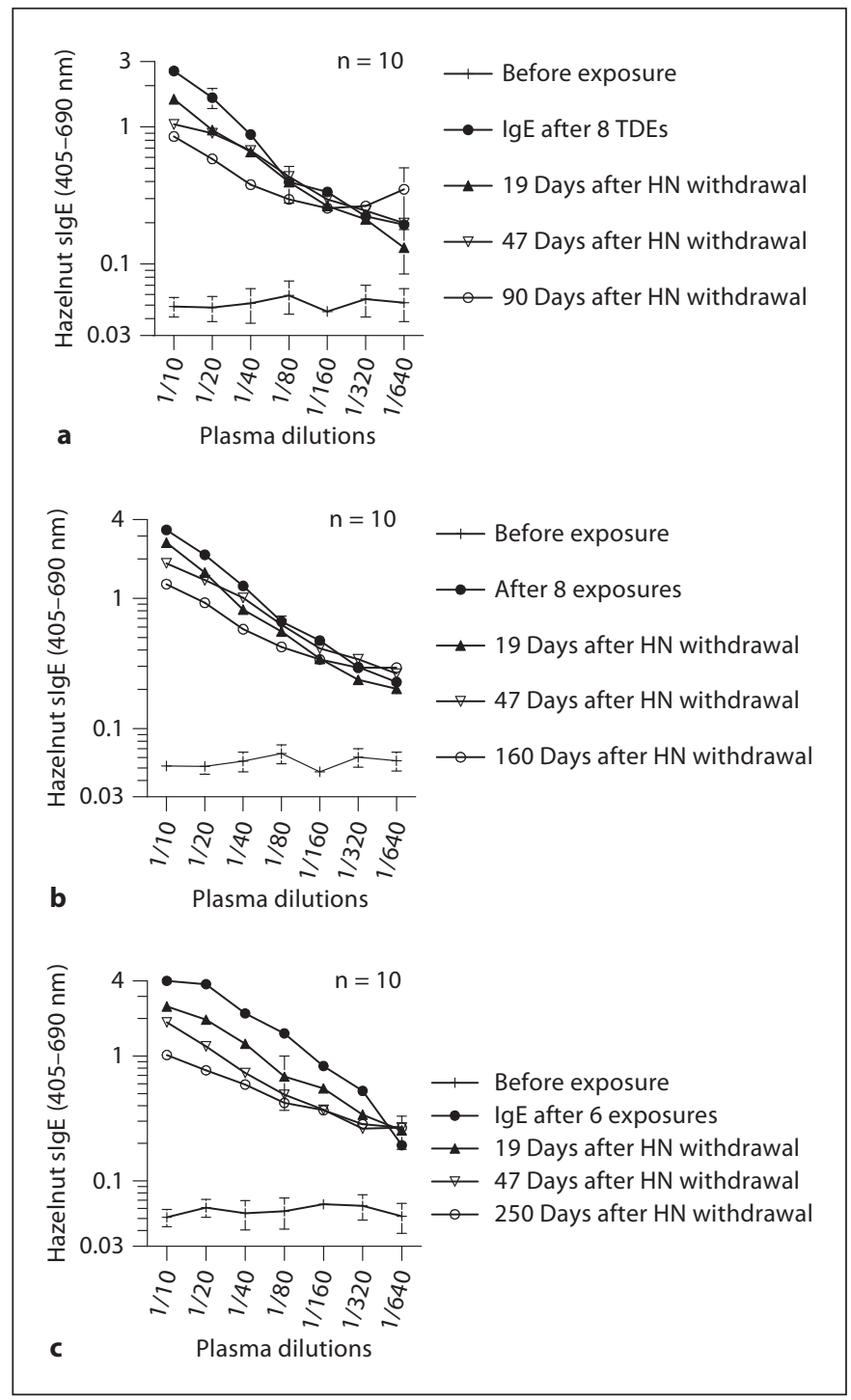

Fig. 1. a-c Circulating hazelnut-specific IgE antibodies persist for long periods despite allergen withdrawal of 3-8 months in BALB/ c mice. Groups of mice ( $n=10$ /group) were transdermally exposed to hazelnut $(\mathrm{HN})$ protein $(0$ or $1 \mathrm{mg} / \mathrm{mouse})$ as described in the Methods; TDE = transdermal exposure. Specific IgE antibody levels were measured before exposure and at several time points after exposure and after allergen withdrawal. The data in a, b and c are from 3-, 5- and 8-month allergen withdrawal experiments, respectively.

Transdermal Sensitization and Long-Term Studies

$\mathrm{BALB} / \mathrm{c}$ female mice were purchased from the Jackson Laboratory (Bar Harbor, Me., USA). Only adult animals (6-8 weeks of age) were used in the study, and they were on casein-free JL Rat \& Mouse/Auto 6F 5K52 lab diet (PMI Nutrition International, Brentwood, Mo., USA). All animal procedures used were in accordance with Michigan State University policies. Trans- 
Fig. 2. a-f Hazelnut elicits an IgE response that is characterized by long-lasting memory in BALB/c mice. Groups of mice $(\mathrm{n}=$ 10 /group) were transdermally exposed to hazelnut protein ( 0 or $1 \mathrm{mg} / \mathrm{mouse}$ ), and then allergen was withdrawn as described in the Methods. Then mice were given two booster transdermal exposures, and their memory IgE levels were measured. a, b Three-month allergen withdrawal experiment. c, d Five-month allergen withdrawal experiment. e, f Eight-month allergen withdrawal experiment. Data shown as means \pm SE. Unpaired t test results: ${ }^{*} \mathrm{p}<0.05$.
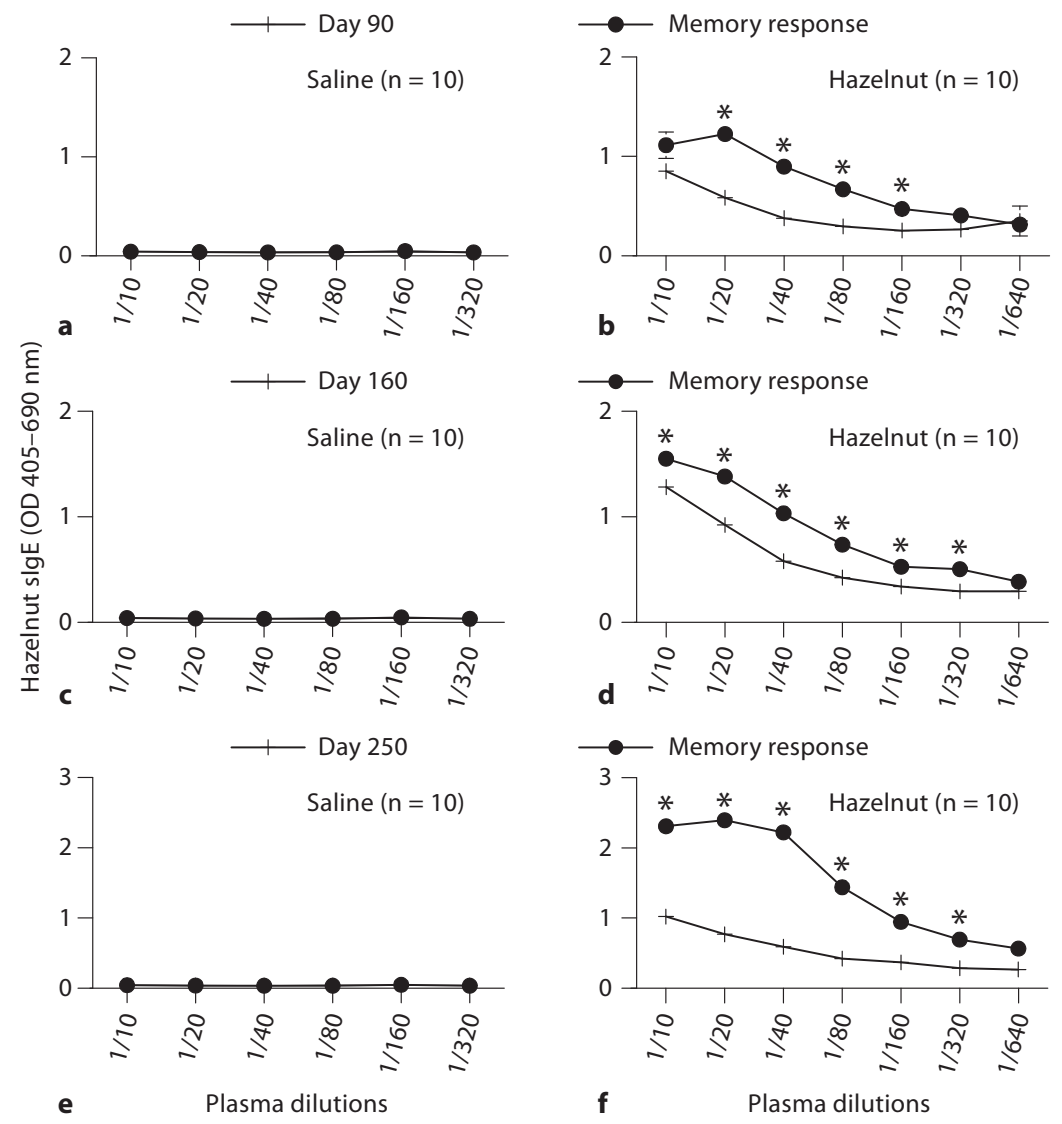

dermal exposure experiments were performed using a modified method that we described before [20]. Groups of mice $(n=10$ per group unless indicated otherwise) were exposed to saline or hazelnut protein ( $1 \mathrm{mg}$ per mouse in saline per application); each mouse had the reagent applied to the skin of the back that had the hair clipped off and covered with a nonlatex nonocclusive bandage for 1 day. Mice were rested for 4 days. Then the cycle of exposure to saline or hazelnut protein was continued for 6-8 weeks until IgE antibodies specific to hazelnut protein were detected.

After sensitization mice were divided into three groups, and allergen was withdrawn for 97 days (3-month study), 162 days (5month study) and 252 days (8-month study). To study memory responses, the first group (3-month study) received 2 transdermal booster exposures with saline or hazelnut protein on day 97 and day 104; the second group (5-month study) received 2 booster exposures with saline or hazelnut protein on day 162 and day 169 , and the third group (8-month study) received 2 transdermal booster exposures with saline or hazelnut protein on day 252 and day 259. Blood samples were collected for every 15 days during the entire period by the saphenous vein, and plasma was used in the antibody analysis.

Long-Term Study on Hazelnut Allergy in Mice

\section{Measurement of Hazelnut-Protein-Specific Antibodies and} Total Plasma IgE Levels

We have previously described optimization of an enzymelinked immunosorbent assay (ELISA) for food-specific IgE and IgG1 antibody analyses [21]. The ELISA procedure used in this study was essentially as described [21].

\section{Induction of Systemic Anaphylaxis, Measurement of Rectal Temperature}

Groups of hazelnut-protein-sensitized and saline-exposed mice were orally challenged with hazelnut protein $(15 \mathrm{mg} / \mathrm{mouse})$ on days 115 (3-month study), 180 (5-month study) and 270 (8month study), respectively, using mouse feeding needles (22 gauge, Popper \& Sons Inc., N.Y., USA). Rectal temperature was measured using a temperature probe (Physitemp Instruments Inc., N.J., USA) before and 30 min after oral challenge. Mice were observed for signs of systemic anaphylaxis during the $60 \mathrm{~min}$ after oral challenge. Clinical scoring (on a scale of zero to 5) was performed by 2 individuals according to the method described here. Scores were: $0=$ no symptoms; $1=$ scratching and rubbing around the nose and head; 2 = puffiness around the eyes and mouth, diarrhea, pili erecti, reduced activity and/or decreased ac- 
Fig. 3. Long-lasting memory IgE response to hazelnut is associated with clinical reactivity and hypothermia response upon oral challenge with hazelnut. Groups of mice ( $n=10$ /group) were transdermally exposed to hazelnut protein ( 0 or $1 \mathrm{mg}$ / mouse) and then allergen was withdrawn as described in the Methods. Later, mice were orally challenged with hazelnut protein (15 mg/mouse) and examined for clinical signs of systemic anaphylaxis during the next 60 min. a, c, e Clinical symptom scores are shown as a scatter plot with each symbol representing 1 mouse. Unpaired t test results: hazelnut, 1 and $0 \mathrm{mg} /$ mouse, $\mathrm{p}<0.05$. b, d, f Rectal temperature before and at $30 \mathrm{~min}$ after oral challenge. a, b Three-month allergen withdrawal experiment. c, d Five-month allergen withdrawal experiment. e, f Eight-month allergen withdrawal experiment. Data shown as means \pm SE. ANOVA test results: bars with different letters are significantly different $(\mathrm{p}<0.05)$.
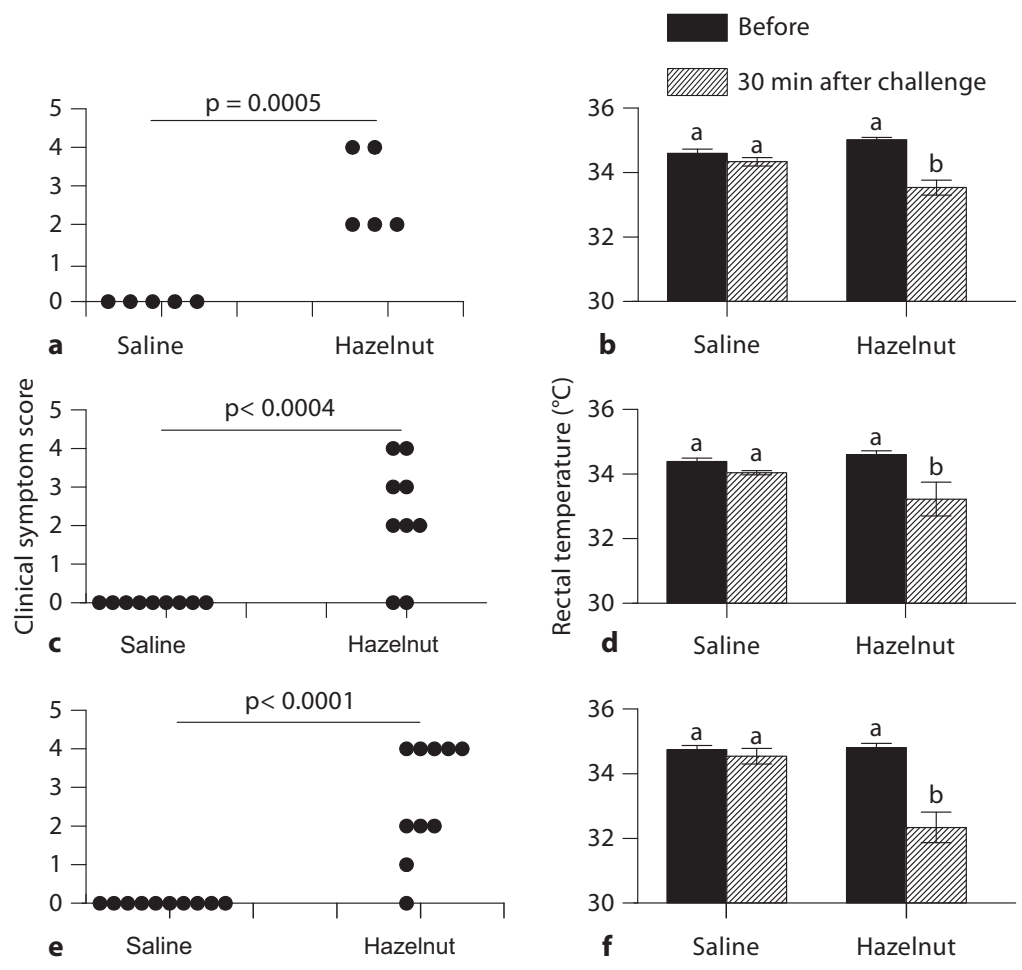

tivity with increased respiratory rate; $3=$ wheezing, labored respiration, cyanosis around the mouth and the tail; $4=$ no activity after prodding, or tremor and convulsions; $5=$ death. Mice were sacrificed within $2 \mathrm{~h}$ after the oral challenge.

Spleen Cell Culture and IL-4 Analysis

Spleen cells were harvested, and standard cell cultures were set up essentially as described [19]. Briefly, spleen cells were cultured $(7.5 \mathrm{million} / \mathrm{ml})$ in the absence and presence of hazelnut protein $(100$ and $500 \mu \mathrm{g} / \mathrm{ml})$. Cell culture supernatants were harvested for use in cytokine analyses using preoptimized ultrasensitive assays (assay sensitivity for IL-4: $3.1 \mathrm{pg} / \mathrm{ml}$ ).

\section{Results}

\section{Allergic (IgE) Response to Hazelnut Once Established \\ Remains Persistent up to 8 Months despite Allergen \\ Withdrawal}

We studied the fate of circulating hazelnut-specific IgE antibodies in three groups of mice that had been sensitized to hazelnut. Thus, following allergen withdrawal, during the 3-month (fig. 1A), 5-month (fig. 1B) and 8month (fig. 1C) withdrawal periods, as expected IgE lev- els started to fall during this period. Nevertheless, significant IgE levels were noted in all three groups despite prolonged allergen withdrawal. Hazelnut-specific IgG1 antibody levels were also persistent in these mice (data not shown).

\section{Memory IgE Response to Hazelnut Persists for Long \\ Periods of Time despite Withdrawal of Allergen \\ Exposure}

In order to test the hypothesis that the hazelnut-elicited IgE response has long-lasting memory, we examined memory IgE responses in these mice upon a booster transdermal exposure to hazelnut. As evident, there was a significant memory IgE response to booster transdermal exposure in these mice after 3, 5 and 8 months of allergen withdrawal (fig. 2).

\section{Memory IgE Response Translates to Clinical Reaction}

of Anaphylaxis and Hypothermia Response upon Oral Challenge with Hazelnut

We examined the clinical symptoms of anaphylaxis and hypothermia response to oral challenge in these 
Fig. 4. Long-lasting allergic responses are associated with memory IL-4 responses. Spleen cells were isolated from BALB/C mice from various groups and cultured with hazelnut protein $(0.1,0.5 \mathrm{mg} / \mathrm{ml})$ or culture medium alone. Cell culture supernatants were harvested on day 3 and analyzed for cytokines using optimized ELISA. a, b Three-month allergen withdrawal experiment. c, d Five-month allergen withdrawal experiment. e, f Eight-month allergen withdrawal experiment. Data shown are averages \pm SE of duplicate analyses. Significance was determined by ANOVA. Bars with different letters are significantly different $(\mathrm{p}<0.05)$.

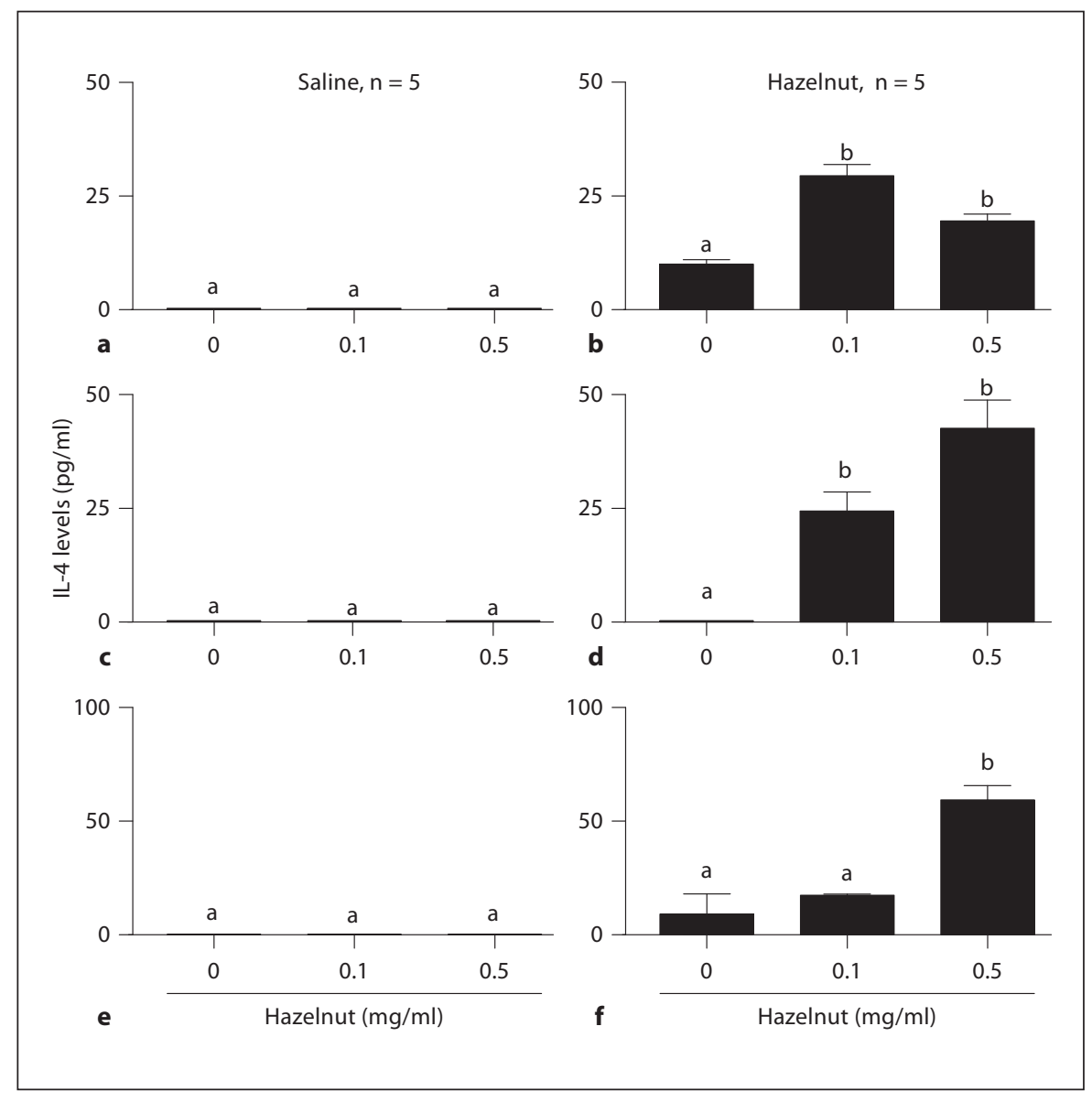

mice. As evident, mice that had been transdermally exposed to saline did not show any significant clinical reactivity. In contrast, mice sensitized to hazelnut (fig. 3) exhibited a consistent clinical reactivity and hypothermia response.

\section{Long-Lasting Allergic Responses Are Associated with}

Memory IL-4 Responses

In order to examine the underlying mechanism of long-lasting hazelnut allergy, we examined the spleen cell IL-4 response to hazelnut. Hazelnut protein significantly activated a recall IL-4 response by spleen cells from hazelnut-allergic mice but not saline control mice (fig. 4).

\section{Discussion}

Here we report several important and novel findings from this study: (i) the IgE response to hazelnut in BALB/ $c$ mice once established remains persistent at significant levels for at least 8 months despite allergen withdrawal; (ii) despite long-term withdrawal of allergen, mice once sensitized to hazelnut exhibit a robust memory IgE response to transdermal allergen exposure; (iii) the memory IgG1 response to hazelnut also remains persistent suggesting that long-lasting memory is not specific to the $\operatorname{IgE}$ isotype per se; rather the immune response to hazelnut is characterized by a long-lasting memory response; (iv) the long-lasting memory IgE response is associated with a memory spleen cell IL- 4 response, and (v) the persistent memory IgE response translates to clinical reactivity and hypothermia responses. These data demonstrate for the first time that clinical sensitization to hazelnut once established persists for a long time in this mouse model due to long-lasting memory IgE and IL-4 responses.

We gave booster exposures because we wanted to determine how long the memory allergic response, as measured by the memory IgE response, persists in this model. We also tested whether such a long-lasting memory $\operatorname{IgE}$ response would be associated with the memory IL- 4 re- 
sponse. We also tested whether the memory IgE response translates to clinical reactivity upon oral challenge.

In this model, upon oral challenge, severe clinical reactions occur very rapidly within $30 \mathrm{~min}$ to $1 \mathrm{~h}$. Therefore, we euthanize the mice by $2 \mathrm{~h}$ upon oral challenge. Consequently, it is not possible to use oral exposure to study the booster effect and to measure the memory $\operatorname{IgE}$ response in this time frame as memory IgE responses need at least a few days to manifest themselves in the peripheral blood. Consequently we used the transdermal route for booster exposures.

We had determined by prior experiments that two transdermal exposures to naïve mice with hazelnut protein in this model do not elicit an IgE response or clinical reactivity upon oral challenge (data not shown). Thus, enhancement in $\operatorname{IgE}$ response to two booster exposures demonstrates a memory IgE response.

We used the BALB/c strain of mice to study long-term characteristics of hazelnut allergy because this strain was used to establish the mouse model of hazelnut allergy that we have described before [19]. Furthermore, since gene knockout mice are available in a BALB/c genetic background, this strain is also suitable for future studies to explore the mechanism of persistence of IL-4, IgE, clinical reactivity and hypothermia response in this model.

The immune and clinical consequences of transdermal exposure to food proteins in humans are unknown at present. A few recent studies including ours demonstrate that transdermal exposure to allergenic food proteins such as hazelnut, ovalbumin, cashew nut and sesame seed can result in clinically significant sensitization $[19,22-24]$. These data demonstrate, for the first time, that just two transdermal exposures during the allergen withdrawal period can trigger a vigorous booster immune response with consequent clinical reactivity upon oral challenge.

Efforts to develop a mouse model of food allergy may be grouped into two types: (i) adjuvant-based approaches and (ii) adjuvant-free approaches [24, 25]. Here we dem- onstrate the utility of an adjuvant-free mouse model of hazelnut allergy to study the long-term characteristics of hazelnut allergy. Furthermore, our findings that hazelnut allergy is a persistent type of food allergy in this mouse model, similar to the human hazelnut disease, adds validity to using this mouse model for further basic and applied studies.

Previous studies focused on elucidating the mechanisms underlying the persistence of other food allergies but not hazelnut allergy. Thus, studies on cow's milk allergy have reported that high levels of IL-4 and inability to develop T regulatory cells (CD4+ CD25+) are the main reasons behind the persistence of cow's milk allergy [13, 17]. Shek et al. [26] reported that the rate of decrease in food-specific IgE levels over time was predictive for the likelihood of developing tolerance in both milk and egg allergy. Another study reported that the trigger for outgrowing hen egg allergy and peanut allergy may be due to the induction of Th1 type cells to produce IFN- $\gamma$ resulting in suppression of the Th2 type response $[15,18]$. Thus, many studies emphasize that long-lasting (Th2 response) IL-4 and IgE levels are vital for the persistence of food allergies.

Here we demonstrate for the first time the long-term characteristics of hazelnut allergy using an adjuvant-free mouse model. Based on these data, we propose that hazelnut elicits a long-lasting memory IL-4 response that sustains a persistent IgE response, thus explaining the mechanism underlying the persistent clinical sensitivity to hazelnut despite allergen withdrawal for long periods of time.

\section{Acknowledgements}

This work was supported by funding from the United States Environmental Protection Agency (STAR grant No. R833133). We thank: Drs. Rob Tempelman, James Pestka, Gale Strasburg, Maurice Bennink, John Linz and Norman Hord for their encouragement and support.
References
Bernhisel-Broadbent J, Dintzis HM, Dintzis RZ, Sampson HA: Allergenicity and antigenicity of chicken egg ovomucoid (Gal d III) compared with ovalbumin (Gal d I) in children with egg allergy and in mice. J Allergy Clin Immunol 1994;93:1047-1059.

-2 Sicherer SH, Sampson HA: Food allergy: recent advances in pathophysiology and treatment. Annu Rev Med 2009;60:261-277.

\footnotetext{
Tariq SM, Stevens M, Matthews S, Ridout S, Twiselton R, Hide DW: Cohort study of peanut and tree nut sensitisation by age of 4 years. BMJ 1996;313:514-517.

4 Sicherer SH, Furlong TJ, Munoz-Furlong A, Burks AW, Sampson HA: A voluntary registry for peanut and tree nut allergy: characteristics of the first 5,149 registrants. J Allergy Clin Immunol 2001;108:128-132.
} 
5 Host A, Halken S, Jacobsen HP, Christensen AE, Herskind AM, Plesner K: Clinical course of cow's milk protein allergy/intolerance and atopic diseases in childhood. Pediatr Allergy Immunol 2002;13(suppl 15):23-28.

6 Boyano-Martinez T, Garcia-Ara C, DiazPena JM, Martin-Esteban M: Prediction of tolerance on the basis of quantification of egg white-specific IgE antibodies in children with egg allergy. J Allergy Clin Immunol 2002;110:304-309.

$\checkmark 7$ Sicherer SH, Sampson HA: Cow's milk protein-specific IgE concentrations in two age groups of milk-allergic children and in children achieving clinical tolerance. Clin Exp Allergy 1999;29:507-512.

$\checkmark 8$ Skolnick HS, Conover-Walker MK, Koerner CB, Sampson HA, Burks W, Wood RA: The natural history of peanut allergy. J Allergy Clin Immunol 2001;107:367-374.

$\checkmark 9$ Fleischer DM, Conover-Walker MK, Matsui EC, Wood RA: The natural history of tree nut allergy. J Allergy Clin Immunol 2005; 116:1087-1093.

10 Crespo JF, Rodriguez J: Food allergy in adulthood. Allergy 2003;58:98-113.

$\checkmark 11$ Ewan PW: Clinical study of peanut and nut allergy in 62 consecutive patients: new features and associations. BMJ 1996;312:10741078.

12 Kagan RS: Food allergy: an overview. Environ Health Perspect 2003;111:223-225.

-13 Tiemessen MM, Van Ieperen-Van Dijk AG, Bruijnzeel-Koomen CA, Garssen J, Knol EF, Van Hoffen E: Cow's milk-specific T-cell reactivity of children with and without persistent cow's milk allergy: key role for IL-10. J Allergy Clin Immunol 2004;113:932-939.
14 Jarvinen KM, Beyer K, Vila L, Chatchatee P, Busse PJ, Sampson HA: B-cell epitopes as a screening instrument for persistent cow's milk allergy. J Allergy Clin Immunol 2002; 110:293-297.

15 Turcanu V, Maleki SJ, Lack G: Characterization of lymphocyte responses to peanuts in normal children, peanut-allergic children, and allergic children who acquired tolerance to peanuts. J Clin Invest 2003;111:10651072 .

16 Schade RP, Van Ieperen-Van Dijk AG, Van Reijsen FC, Versluis C, Kimpen JL, Knol EF, Bruijnzeel-Koomen CA, Van Hoffen E: Differences in antigen-specific T-cell responses between infants with atopic dermatitis with and without cow's milk allergy: relevance of Th2 cytokines. J Allergy Clin Immunol 2000;106:1155-1162.

17 Karlsson MR, Rugtveit J, Brandtzaeg P: Al lergen-responsive $\mathrm{CD} 4+\mathrm{CD} 25+$ regulatory T cells in children who have outgrown cow's milk allergy. J Exp Med 2004;199:16791688.

18 Noma T, Yoshizawa I, Aoki K, Yamaguchi K, Baba M: Cytokine production in children outgrowing hen egg allergy. Clin Exp Allergy 1996;26:1298-1307.

19 Birmingham NP, Parvataneni S, Hassan HM, Harkema J, Samineni S, Navuluri L, Kelly CJ, Gangur V: An adjuvant-free mouse model of tree nut allergy using hazelnut as a model tree nut. Int Arch Allergy Immunol 2007; 144:203-210.
20 Birmingham N, Gangur V, Samineni S, Navuluri L, Kelly C: Hazelnut allergy: evidence that hazelnut can directly elicit specific IgE antibody response via activating type 2 cytokines in mice. Int Arch Allergy Immunol 2005; 137:295-302.

21 Birmingham N, Payankaulam S, Thanesvorakul S, Stefura B, Hay Glass K, Gangur V: An ELISA-based method for measurement of food-specific IgE antibody in mouse serum: an alternative to the passive cutaneous anaphylaxis assay. J Immunol Methods 2003; 275:89-98.

22 Hsieh KY, Tsai CC, Wu CH, Lin RH: Epicutaneous exposure to protein antigen and food allergy. Clin Exp Allergy 2003;33:10671075.

23 Navuluri L, Parvataneni S, Hassan H, Birmingham NP, Kelly C, Gangur V: Allergic and anaphylactic response to sesame seeds in mice: identification of Ses i 3 and basic subunit of 11s globulins as allergens. Int Arch Allergy Immunol 2006; 140:270-276.

24 Parvataneni S, Gonipeta B, Tempelman RJ, Gangur V: Development of an adjuvant-free cashew nut allergy mouse model. Int Arch Allergy Immunol 2009;149:299-304.

25 Li XM, Schofield BH, Huang CK, Kleiner GI, Sampson HA: A murine model of IgE-mediated cow's milk hypersensitivity. J Allergy Clin Immunol 1999;103:206-214.

26 Shek LP, Soderstrom L, Ahlstedt S, Beyer K, Sampson HA: Determination of food specific IgE levels over time can predict the development of tolerance in cow's milk and hen's egg allergy. J Allergy Clin Immunol 2004; 114:387-391. 